doi: $10.12957 /$ childphilo.2021.62884

\title{
¿qué dicen los manuales de historia sobre la infancia? análisis de textos escolares chilenos
}

\author{
humberto álvarez sepúlveda 1 \\ universidad católica de la santísima concepción, concepción, chile \\ orcid id: https:/ / orcid.org/0000-0001-5729-3404
}

resumen

Los textos escolares de historia en Chile se caracterizan por exponer una narrativa histórica adultocéntrica que invisibiliza la participación de los niños y niñas, ya que tradicionalmente se han centrado en describir las hazañas políticas protagonizadas por hombres adultos de la élite en la historia nacional y occidental. Para evidenciar esta problemática, en esta investigación cualitativa, de carácter exploratorio e interpretativo, se utiliza la literacidad crítica para analizar los textos e imágenes de cuatro libros escolares publicados entre los años 2016 y 2019 por las editoriales SM y Santillana. De estos manuales, se seleccionaron unidades temáticas relacionadas con la Roma y Grecia Antigua, el Chile colonial y la historia europea del siglo XIX y XX porque son las que cuentan con la mayor cantidad de evidencias pertinentes para examinar el tema. Se concluye que los discursos analizados demuestran que los infantes son actores sociales marginados de la historia o bien son representados desde el paradigma adultocéntrico como sujetos dependientes y subordinados al mundo adulto. Frente a este escenario, se insiste en la importancia de priorizar las perspectivas infantiles en el estudio de la historia y en la problematización de los contenidos históricos que se enseñan en el aula.

palabras clave: historia; infancia; texto escolar; chile; representación discursiva.

\section{what do history manuals say about childhood? analysis of chilean school textbooks}

abstract

History textbooks in Chile are characterized by exposing an adult-centered historical narrative that invisibilizes the participation of boys and girls, since they have traditionally focused on describing the political exploits carried out by elite adult men in national and western history. To evidence this problem, in this qualitative, exploratory and interpretive research, critical literacy is used to analyze the texts and images of four textbooks published between 2016 and 2019 by SM and Santillana publishers. From these manuals, thematic units related to Ancient Rome and Greece, colonial Chile, and European history of the 19th and 20th centuries were selected because they have the most relevant evidence to examine the subject. It is concluded that the analyzed discourses show that infants are marginalized social actors in history or are represented from the adult-centered paradigm as dependent and subordinate subjects to the adult world. Faced with this scenario, the importance of prioritizing children's perspectives in the study of history and in the problematization of historical contents taught in the classroom is emphasized.

\footnotetext{
${ }^{1}$ Email: humalvarezsep@gmail.com
} 
¿qué dicen los manuales de historia sobre la infancia? análisis de textos escolares chilenos

keywords: history; childhood; textbooks; chile; discursive representation.

\section{o que dizem os livros didáticos de história sobre a infância? análise de textos escolares chilenos}

\section{resumo}

No Chile, os livros didáticos de história se caracterizam por expor uma narrativa histórica centrada no adulto que torna invisível a participação de meninos e meninas, uma vez que tradicionalmente se concentram em descrever as façanhas políticas realizadas por homens adultos de elite na história nacional e ocidental. Para demonstrar esse problema, nesta pesquisa qualitativa, exploratória e interpretativa, o letramento crítico é utilizado para analisar os textos e imagens de quatro livros didáticos publicados entre 2016 e 2019 pelas editoras SM e Santillana. Destes manuais, foram selecionadas unidades temáticas relacionadas à Roma e à Grécia Antiga, ao Chile colonial e à história europeia dos séculos XIX e XX, por conterem as evidências mais relevantes para o exame do assunto. Conclui-se que os discursos analisados mostram que os bebês são atores sociais marginalizados da história ou são representados a partir do paradigma adultocêntrico como sujeitos dependentes e subordinados ao mundo adulto. Diante desse cenário, destaca-se a importância de priorizar as perspectivas das crianças no estudo da história e na problematização dos conteúdos históricos ministrados em sala de aula.

palavras-chave: história; infância; livro didático; chile; representação discursiva. 
¿qué dicen los manuales de historia sobre la infancia? análisis de textos escolares chilenos

\section{introducción}

La Convención sobre los Derechos del Niño aprobada en 1989 y las recientes aportaciones historiográficas sobre la infancia, como los trabajos de Pagès y Villalón (2013) y de Rojas (2016), han permitido visibilizar la importancia de los/as niños/as en el devenir histórico y en la sociedad chilena. Pese a ello, este reconocimiento no ha permeado el curriculum de Historia, Geografía y Ciencias Sociales, ni los manuales escolares de la asignatura entregados por el Ministerio de Educación de Chile, ya que los infantes siguen siendo invisibilizados por la perspectiva adultocéntrica dominante en estos insumos. Siguiendo a Jara (2018) y a Morales (2020), dicho etnocentrismo se centra en subrayar las hazañas políticas lideradas por hombres adultos insignes en el pasado.

La gran cobertura que tienen los textos escolares de historia en los colegios públicos y particulares subvencionados de Chile ha favorecido la función homogeneizadora de estos dispositivos curriculares, que tienen como propósito difundir los conocimientos históricos concebidos desde la perspectiva adulta y que los estudiantes deben aprender para convertirse en ciudadanos "buenos" que no cuestionen el orden establecido.

Como señalan Pagès y Villalón (2013), el adultocentrismo se observa transversalmente en el abordaje de todos los periodos históricos, ya sean de Chile o del mundo. Esto resulta sumamente preocupante en la actualidad porque, siguiendo a Sosenski (2015), el paradigma adultocéntrico, que busca formar al alumnado según los valores y tradiciones socio-civilizatorias dominantes del pensamiento occidental, se encuentra completamente descontextualizado para promover aprendizajes históricos significativos que permitan al alumnado comprender el mundo actual desde la diversidad y afrontar la incertidumbre que imponen las constantes crisis del proceso globalizador a las sociedades presentes. 
¿qué dicen los manuales de historia sobre la infancia? análisis de textos escolares chilenos

Con el fin de forjar nuevas lecturas críticas en la historia enseñada y de evaluar la invisibilización de los/as niños/as en el curriculum de Historia, Geografía y Ciencias Sociales de Chile, se analizan en este artículo el discurso escrito e iconográfico de cuatro libros de texto publicados entre los años 2016 y 2019 por las editoriales SM y Santillana. De estos manuales, se han seleccionado unidades temáticas relacionadas con el Chile colonial, las civilizaciones clásicas (Roma y Grecia Antigua) y la historia europea del siglo XIX y XX, pues son las que cuentan con la mayor cantidad de evidencias para establecer una primera aproximación sobre las representaciones de la infancia en los manuales previstos debido a que no existen estudios afines que estudien esta temática.

Esta investigación se realiza bajo la convicción de que puede motivar a los docentes de la especialidad a cuestionar el paradigma adultocéntrico presente en los manuales escolares, a incorporar la infancia como una categoría significativa en la historia enseñada y a generar procesos de empatía histórica en los niños y jóvenes estudiantes con respecto al rol que tuvieron sus pares en el pasado.

\section{repensando el paradigma adultocéntrico en la historia: tensiones y nuevas voces}

Desde la institucionalización de la historia como asignatura escolar en Chile a mediados del siglo XIX, el curriculum y la enseñanza de la disciplina se han basado en el adultocentrismo para abordar temáticas que contribuyan a la consolidación nacional del país, como el estudio de los próceres de la patria y de las proezas de la clase política, y al entendimiento de la historia de Europa Occidental, que comprende la historia de la antigua Grecia y Roma y la historia medieval, moderna y contemporánea del viejo continente (Pagès y Villalón, 2013; Zuñiga, 2015).

Uno de los grandes axiomas propositivos de la visión adultocéntrica sostiene que la historia está dirigida por el mundo adulto, donde los niños y las niñas son actores periféricos que se encuentran supeditados a este estamento. Este rasgo, siguiendo a Zúñiga (2015), se ha visto acentuado por el predominio de la historia política y bélica y por el tratamiento de los hombres ilustres que han aportado a la configuración de la idea de progreso vigente en cada periodo histórico. 
La prevalencia del adultocentrismo en la historia enseñada y en el curriculum de la asignatura es concomitante con la incontrarrestable hegemonía de este paradigma en la disciplina histórica; sin embargo, esta última va más adelantada, pues desde los años sesenta han surgido diversos trabajos que posicionan el rol del infante (DeMause, 1974; Ariès, 1987; Osta y Espiga, 2017; Rubiera, 2018; Vicente, 2020), mientras que, en la escuela, el discurso que releva la actuación histórica de los niños y las niñas es prácticamente inexistente en Chile y en el resto de los países latinoamericanos (Pagès y Villalón, 2013; Sosenski y Jackson, 2013; Sosenki, 2015; Gonzaga, Santiago y Goulart, 2018). En esta línea, cabe destacar que la historia de la infancia ha tenido un creciente auge gracias a los avances de la historia social y cultural que han atenuado el protagonismo de la historia política. Las aportaciones pioneras que posibilitaron este ascenso fueron los estudios de Philippe Ariès y de Lloyd DeMause.

En su obra El niño y la vida familiar en el Antiguo Régimen, Ariès examina la historia de la infancia hasta el siglo XVIII, donde el foco de investigación no está puesto en la vida de los niños sino en las representaciones que el mundo adulto tenía sobre estos. Para Ariès (1987), la infancia, tal y como la conocemos hoy, no existía en la sociedad medieval porque la interacción entre niño y adulto que se suscitaba desde el nacimiento en el contexto de la vida rural provocó que los distintos grupos etarios se mezclaran y perdieran relevancia. Con respecto a la edad moderna, Ariès (1987) señala que la educación tuvo un importante papel en la construcción de la identidad infantil, ya que era uno de los pilares claves de la idea de progreso que prevalecía en esa época.

Por su parte, Lloyd DeMause en su libro Historia de la infancia estudió, desde la perspectiva del mundo adulto, los cambios históricos producidos en la concepción social sobre la infancia. Para ello, DeMause (1974) analiza la dependencia del niño con el adulto, donde predomina el maltrato físico y psicológico contra el infante como un rasgo común y naturalizado dentro de la historia. De igual modo, DeMause (1974) concibe la existencia de un desarrollo psíquico progresivo en la mentalidad occidental, pues sostiene que las transiciones generacionales de la sociedad adulta son el resultado de los cambios generados por las interacciones entre padres e hijos. 
¿qué dicen los manuales de historia sobre la infancia? análisis de textos escolares chilenos

Autores posteriores profundizan en los aspectos desarrollados por Ariès y DeMause y llegan a cuestionar sus enfoques. Los primeros eruditos en debatir sus contribuciones fueron los historiadores Lawrence Stone y Linda Pollock. Stone (1990) señala que los problemas que surgen al analizar la mayor parte de las obras de DeMause y de Ariès se deben a que tratan la historia de la infancia en forma aislada, pues no suelen considerar el contexto familiar, que es la institución principal en donde se desarrolla el proceso de socialización del niño.

Por su parte, Linda Pollock en su obra Los niños olvidados. Relaciones entre padres e hijos de 1500 a 1900 crítica una parte importante de los aportes de Ariès y de DeMause, ya que tienden a concluir que los niños fueron maltratados y que la relación entre padres e hijos solía ser distante. Al respecto, Pollock (1990) sostiene que no se puede generalizar porque los padres no siempre trataban mal a sus hijos, pues la relación existente entre ellos también se fundamentaba en el cariño y la preocupación por su bienestar.

El estudio de Eduardo Ciafardo llamado Los niños en la ciudad de Buenos Aires (1890-1910) publicado en 1992 es una propuesta que amplía el marco de acción de la historia de la infancia, ya que, más que interesarse en las relaciones entre padres e hijos o de estudiar en qué periodo histórico surge la noción de infancia, tiene como propósito analizar la vida cotidiana de los niños, que abarca desde el estudio de los juguetes y los juegos que realizaban los menores, pasando por la vestimenta que utilizaban, hasta las modalidades de crianza dominantes. A diferencia de los estudios liderados por Philippe Ariès, Linda Pollock y Lloyd DeMause, la investigación de Ciafardo no se centra solamente en el estudio de los niños de la clase alta sino también en aquellos que pertenecen a los sectores pobres y medios, los cuales, para este trabajo en particular, conformaban la sociedad bonaerense de finales del siglo XIX y comienzos del siglo XX.

El enfoque holístico desarrollado por Ciafardo se observa en el libro Historia de la infancia en el Chile Republicado (1810-2010) de Jorge Rojas, puesto que afronta la tarea de construir el proceso de incorporación de la infancia a la sociedad, considerando las dimensiones sociales, culturales y normativas. Siguiendo este propósito, Rojas (2016) 
aborda diversos temas en dicha obra, tales como el rol de los niños durante la guerra de la Independencia, la cultura que los rodeó en aquella época, los patrones de crianza y las diferentes formas de ser familia desde que Chile nace como nación soberana hasta la actualidad.

A partir de los trabajos citados, la investigación sobre la historia de la infancia se ha consolidado como un campo específico dentro de la disciplina histórica. Sin embargo, a pesar del auge alcanzado, los historiadores de la infancia no se han puesto de acuerdo en el momento en que esta etapa de la vida es reconocida y valorada socialmente. Tampoco hay consenso sobre la vigencia o la duración de la infancia, aunque, como argumenta Salinas (2001), cabe destacar que se han utilizado criterios cronológicos cuando se intenta precisar la condición de la niñez y su paso a la adolescencia o a la vida adulta.

Más allá de la falta de acuerdo en torno a las cuestiones previstas, vale la pena resaltar que la creciente importancia de la historia de la infancia, sumada a la aprobación de la Convención sobre los Derechos del Niño en 1989 y a la mayor sensibilidad social sobre la niñez por parte del mundo adulto, han contribuido a la identificación formal de este período en la vida humana y al reconocimiento de la autonomía de los niños y niñas como actores sociales.

En este contexto, resulta indispensable incorporar a los infantes en el curriculum de Historia, Geografía y Ciencias Sociales de Chile y en la enseñanza de la disciplina para atenuar su ausencia y resignificar su participación en el discurso histórico. Para Sosenski (2015), esta nueva forma de pensar la historia implica superar la narrativa tradicional, centrada en las acciones de los hombres adultos, y pasar a un nuevo relato donde el estudio de la infancia y su respectiva enseñanza reivindique a los niños y niñas como agentes sociales y no sólo como sujetos subordinados al poder de los adultos.

aproximación al curriculum de historia, geografía y ciencias sociales vigente en chile 
¿qué dicen los manuales de historia sobre la infancia? análisis de textos escolares chilenos

El curriculum de historia vigente en Chile desde 2013 expresa el modo en que la clase dirigente del país desea proyectar la historia que los alumnos y alumnas deben aprender para que sean ciudadanos/as preparados/as para convivir de acuerdo a los cánones institucionales establecidos (Gazmuri, 2017; Pagès, Villalón y Zamorano, 2017; Marín, 2020). De tal modo, el curriculum de la asignatura es un acto político y pedagógico que representa la visión de mundo de los sectores dominantes que se autoproclaman el rol de ser dueños de las verdades históricas universales que han dirigido el pasado y el presente.

Para Álvarez (2021), dicho posicionamiento hegemónico se fundamenta en saberes curriculares previamente elegidos que suprimen los aspectos o actores sociales que no contribuyen al modelo de formación cívica que se busca implantar en las instituciones educativas del país. Dentro de este relato, la narración de hazañas políticas, militares y económicas de insignes hombres adultos en la historia occidental y chilena constituye el eje transversal del curriculum de Historia, Geografía y Ciencias Sociales, mientras que el estudio sobre los infantes como sujetos históricos es un apartado prácticamente inexistente en este marco normativo.

El curriculum de la asignatura está compuesto por los Planes de Estudio, las Bases Curriculares y los Programas de Estudio; sin embargo, para efectos de esta investigación, se abordarán brevemente solo los dos últimos. Las Bases Curriculares constituyen el principal itinerario formativo del curriculum y su objetivo es fijar los objetivos de aprendizaje esperados que deben lograr los estudiantes en cada nivel educativo. Este insumo curricular sostiene que la asignatura de Historia, Geografía y Ciencias Sociales tiene como propósito desarrollar conocimientos, habilidades y actitudes necesarias para que los estudiantes puedan comprender la complejidad de la realidad social y el devenir de nuestra sociedad y ser ciudadanos/as responsables y comprometidos/as con la democracia, el bien común y el respeto a los derechos humanos (Bases Curriculares de $7^{\circ}$ básico a $2^{\circ}$ Medio, 2016).

Por su parte, los Programas de Estudio corresponden a un marco orientativo indispensable para llevar a cabo la planificación, organización y evaluación de los 
aprendizajes de la asignatura en el aula. En su preámbulo, los Programas de Estudio de Historia, Geografía y Ciencias Sociales señalan que esta materia escolar busca analizar al ser humano en su dimensión individual y social desde diversas perspectivas, entre las que se cuentan, además de la Historia y la Geografía, la Economía, la Demografía, la Sociología y la Ciencia Política, ya que "el trabajo conjunto de estas disciplinas permite al alumno desarrollar las competencias necesarias para desenvolverse como un ciudadano capaz de actuar responsable y críticamente en la sociedad, y para enfrentar los desafíos del mundo globalizado" (Programa de Estudio de Historia, Geografía y Ciencias Sociales de $6^{\circ}$ básico, 2018, p. 30).

En ambos insumos curriculares se suscita el estudio integrado de la historia con las ciencias sociales para fomentar la ciudadanía activa y el desarrollo de la sociedad; sin embargo, el tratamiento exiguo y anecdótico de la otredad -especialmente de los niños y niñas- en el curriculum obstruye, en gran parte, la concreción de dicho objetivo porque impide el reconocimiento de los derechos humanos de todos(as) y la promoción de la lucha social contra el adultocentrismo (Pagès y Villalón, 2013; Sosenki, 2015; Gonzaga, Santiago y Goulart, 2018).

Esta contrariedad presente en el curriculum de Historia, Geografía y Ciencias Sociales se ha convertido en un gran obstáculo para reivindicar a los niños y niñas como agentes de cambio en la historia escolar, ya que su extendida y transversal invisibilización en el curriculum no permite visibilizar su importancia en los hechos históricos o deconstruir una historia alejada de la perspectiva adultocéntrica.

\section{el texto escolar de historia como dispositivo de difusión del discurso histórico adultocéntrico}

En los últimos decenios, los manuales de historia en Chile han sido fuentes documentales privilegiadas para examinar, a través del análisis discursivo, las representaciones sobre determinados personajes, hechos o perspectivas históricas que dominan el discurso escrito e iconográfico (Fernández, 2010; Pagès y Villalón, 2013; Canales, Fernández y Rubio, 2018; Marín, 2020; Álvarez, 2021). 
¿qué dicen los manuales de historia sobre la infancia? análisis de textos escolares chilenos

Un tema de especial interés son las representaciones sobre la infancia presentes en los textos escolares de historia, ya que son muy escasos los estudios que demuestran que dichos insumos curriculares buscan enaltecer el estudio de las experiencias y prácticas de los adultos y negar los comportamientos, acciones y perspectivas infantiles. Esto se observa, de forma frecuente, en el uso de categorías léxicas que suprimen total o parcialmente la actuación de los infantes en la historia, en el predominio de imágenes estereotipadas y en la presencia de narrativas históricas descriptivas que constantemente ponen énfasis en el protagonismo de los hombres adultos en la historia política y bélica de Chile y de la Europa Occidental.

Lo anterior ha sido plasmado por Pagès y Villalón (2013), quienes señalan que los textos escolares de los países de América Latina y de Europa desarrollan y privilegian en sus discursos la historia adulta, androcéntrica y eurocéntrica de las sociedades pasadas y presentes. En este relato, los niños tienden a ser presentados como sujetos pasivos y receptores de la acción adulta o bien son utilizados para ejemplificar alguna situación histórica que sea potencialmente socializadora, pues nunca aparecen vinculados a contenidos controversiales o relevantes como, por ejemplo, su lugar en la familia, el trabajo, la política o la desigualdad económica.

Es evidente que, según lo narrado, los libros de texto funcionan como dispositivos curriculares que legitiman el adultocentrismo en la historia y en el sistema educativo actual, pues si se repite de forma constante, ya sea en forma oral o escrita, que la historia está hecha por y para los adultos, es muy probable que la transmisión de convicciones e ideologías provistas desde dicho grupo contribuyan al surgimiento de estereotipos culturales que atenúen o anulen la actuación histórica de los/as niños/as.

De esta forma, el manual escolar, entendido como un artefacto cultural (Espinoza, 2012; Lester y Labraña, 2018), privilegia formas de conocimiento asociadas al adultocentrismo y menosprecia a otras interpretaciones históricas contrarias a dicho paradigma. En esta línea, es importante señalar que los textos chilenos tienen cuatro propósitos muy claros y precisos: comprender la evolución histórica del país en 
relación a los procesos colonizadores y civilizatorios liderados por hombres adultos europeos; fortalecer la identidad nacional; reconocer el rol de los hombres adultos ilustres que protagonizaron la historia chilena y occidental; y preparar a los niños y niñas como ciudadanos/as capaces de resguardar el statu quo.

La concreción de los objetivos formativos de los libros de texto se ve facilitada porque, tal como señala Marolla (2019), los docentes de la asignatura rara vez cuestionan el discurso histórico escolar, lo cual presupone la existencia de una censura a las voces alternativas o críticas. Esto favorece el posicionamiento del saber adultocéntrico como prácticamente la única gran narrativa del conocimiento histórico escolar, la cual, a través del proceso de escolarización imperante, se convierte en un poderoso discurso de reproducción y de legitimación ideológica en la formación del alumnado. Esta situación ha llevado a instaurar la lógica adultocéntrica como un habitus, es decir, siguiendo a Bourdieu (2008), un espacio simbólico que no solo describe la diferencia entre adultez y niñez, sino que también naturaliza el adultocentrismo en el orden establecido. Como sostiene Jara (2018), el discurso adulto tiende a lo autoritario y a considerar a los infantes como individuos incapaces y sumisos, lo que se traduce en prácticas correctivas, coercitivas o negadoras "por el bien del niño". Por tal motivo, en el plano educativo, los saberes históricos sobre los niños y niñas son continuamente relegados a un contexto de menor relevancia.

\section{metodología}

La investigación es cualitativa, de carácter exploratorio e interpretativo, cuyo propósito es obtener una primera aproximación acerca de las representaciones sobre la infancia que están presentes en los textos escolares de Historia, Geografía y Ciencias Sociales.

La muestra utilizada es intencionada y está conformada por cuatro textos escolares de dicha especialidad de las editoriales SM y Santillana, cuyos insumos curriculares fueron entregados por el Ministerio de Educación durante el periodo 20162019 a los establecimientos municipales y particulares subvencionados de Chile. Cabe 
¿qué dicen los manuales de historia sobre la infancia? análisis de textos escolares chilenos

destacar que las empresas enunciadas tienen una gran presencia en el territorio nacional y que ambas siguen una línea editorial tradicional marcada por el paradigma adultocéntrico.

Con la finalidad de analizar en forma transversal los discursos presentes en los manuales de historia, se seleccionaron libros de textos pertenecientes al segundo ciclo de Enseñanza Básica y a la Educación Media (tabla 1). De estos se eligieron unidades temáticas relacionadas con el Chile colonial, las civilizaciones clásicas (Roma y Grecia Antigua) y la historia europea del siglo XIX y XX, ya que en estas se concentra la mayor parte de las evidencias que permiten visibilizar las representaciones sobre los niños y niñas que son referenciados/as en el contexto de la historia nacional y occidental.

Tabla 1. Muestra de manuales escolares

\begin{tabular}{|c|c|c|c|c|c|}
\hline Año & Autor(es) & Texto & Editorial & $\begin{array}{c}\text { Grupo } \\
\text { propietario/ } \\
\text { Línea } \\
\text { editorial }\end{array}$ & Unidad temática analizada \\
\hline 2019 & Paulo Flores & $\begin{array}{l}\text { Historia, } \\
\text { Geografía y } \\
\text { Ciencias Sociales } \\
5^{\circ} \text { básico }\end{array}$ & $\begin{array}{l}\text { Editorial } \\
\text { SM }\end{array}$ & $\begin{array}{l}\text { Grupo SM/ } \\
\text { Tradicional }\end{array}$ & $\begin{array}{l}\text { Unidad III. “¿Qué tipo de sociedad } \\
\text { se formó durante la Colonia?” (págs. } \\
\text { 110-165). }\end{array}$ \\
\hline 2019 & $\begin{array}{l}\text { Gonzalo Beltrán } \\
\text { Francisco Fuentes } \\
\text { Pedro Panza } \\
\text { Carolina Valdés }\end{array}$ & $\begin{array}{l}\text { Historia, } \\
\text { Geografía y } \\
\text { Ciencias Sociales } \\
7^{\circ} \text { básico }\end{array}$ & $\begin{array}{l}\text { Editorial } \\
\text { SM }\end{array}$ & $\begin{array}{l}\text { Grupo SM/ } \\
\text { Tradicional }\end{array}$ & $\begin{array}{l}\text { Unidad II. “¿En qué ámbitos de las } \\
\text { sociedades actuales se aprecia la } \\
\text { influencia de las civilizaciones } \\
\text { clásicas?" (págs. 68-119). }\end{array}$ \\
\hline 2017 & $\begin{array}{l}\text { Sofía Honeyman } \\
\text { Camila Silva } \\
\text { Sebastián } \\
\text { Quintana } \\
\text { Carolina } \\
\text { Santelices } \\
\end{array}$ & $\begin{array}{l}\text { Historia, } \\
\text { Geografía y } \\
\text { Ciencias Sociales } \\
2^{\circ} \text { medio }\end{array}$ & Santillana & $\begin{array}{l}\text { Grupo Prisa/ } \\
\text { Tradicional }\end{array}$ & $\begin{array}{l}\text { Unidad I. "Crisis, totalitarismos y } \\
\text { guerra" (págs. 18-77). }\end{array}$ \\
\hline 2016 & $\begin{array}{l}\text { José Morales } \\
\text { Sergio Pastene } \\
\text { Carolina } \\
\text { Santelices } \\
\text { Sebastián } \\
\text { Quintana }\end{array}$ & $\begin{array}{l}\text { Historia, } \\
\text { Geografía y } \\
\text { Ciencias Sociales } \\
1^{\circ} \text { medio }\end{array}$ & Santillana & $\begin{array}{l}\text { Grupo Prisa/ } \\
\text { Tradicional }\end{array}$ & $\begin{array}{l}\text { Unidad III. "El progreso indefinido y } \\
\text { sus contradicciones" (págs. 132-191). }\end{array}$ \\
\hline
\end{tabular}

Fuente: Elaboración propia (2021).

Para analizar los manuales previstos, se utiliza la perspectiva de la literacidad crítica (Ortega y Pagès, 2017; Marolla y Solís, 2021) porque permite interpretar sus textos e imágenes según las categorías apriorísticas de la tabla 2, pues posibilita el desarrollo de un proceso reflexivo que ayuda a analizar el discurso de acuerdo con los 
contextos, las prácticas sociales y las relaciones de poder existentes entre el mundo adulto y los infantes.

Tabla 2. Matriz de análisis

\begin{tabular}{|l|}
\hline Texto: \\
\hline Autor: \\
\hline Editorial: \\
\hline Año: \\
\hline
\end{tabular}

\begin{tabular}{|c|c|}
\hline \multicolumn{2}{|l|}{ Nombre de la Unidad: } \\
\hline Categorías & Descriptor \\
\hline $\begin{array}{l}\text { Representación basada en } \\
\text { una concepción de } \\
\text { dependencia }\end{array}$ & $\begin{array}{l}\text { Representa a los actores sociales como sujetos } \\
\text { dependientes y subordinados a un grupo dominante } \\
\text { dentro del orden social establecido. }\end{array}$ \\
\hline $\begin{array}{l}\text { Supresión de los actores } \\
\text { sociales }\end{array}$ & $\begin{array}{l}\text { Pretende negar u omitir a los sujetos que no son relevantes } \\
\text { en la historia oficial; por tanto, no se precisa su } \\
\text { participación dentro de los acontecimientos o procesos } \\
\text { históricos. }\end{array}$ \\
\hline Representación "neutral" & $\begin{array}{l}\text { Representa a los sujetos de forma descriptiva, "imparcial" } \\
\text { y anecdótica. Pretende la «neutralidad» en el discurso para } \\
\text { evitar la entrega de información interpretativa y } \\
\text { significativa, que permita al lector formarse un juicio } \\
\text { crítico y fundamentado sobre la participación de los } \\
\text { sujetos invisibilizados en la historia oficial. }\end{array}$ \\
\hline $\begin{array}{l}\text { Generalización a partir de } \\
\text { la asignación de rasgos } \\
\text { comunes }\end{array}$ & $\begin{array}{l}\text { Se usa para asignar rasgos comunes que presuntamente } \\
\text { son exclusivos de un grupo o clase social, los cuales } \\
\text { denotan un trato despectivo y sesgado hacia dicho } \\
\text { colectivo. }\end{array}$ \\
\hline $\begin{array}{l}\text { Generalización a partir de } \\
\text { singulares y plurales } \\
\text { masculinos }\end{array}$ & $\begin{array}{l}\text { Por medio del uso de singulares y plurales masculinos } \\
\text { busca presentar a los agentes sociales claves } \\
\text { (especialmente a las mujeres y niñas) de forma colectiva y } \\
\text { anónima para suprimir sus identidades y liderazgos en la } \\
\text { narración de los hechos históricos. }\end{array}$ \\
\hline $\begin{array}{l}\text { Etiqueta del discurso de la } \\
\text { domesticidad }\end{array}$ & $\begin{array}{l}\text { Es utilizada para restringir la acción de los actores sociales } \\
\text { al ámbito doméstico resguardado por las mujeres. }\end{array}$ \\
\hline $\begin{array}{l}\text { Estereotipación basada en } \\
\text { la concepción de "mayoría } \\
\text { de edad" }\end{array}$ & $\begin{array}{l}\text { Pretende asociar la madurez psicológica y física del sujeto } \\
\text { con la edad que se considera culturalmente como el inicio } \\
\text { de la etapa adulta y que, generalmente, está establecida en } \\
\text { la constitución de cada país para garantizar algunos } \\
\text { derechos como el sufragio, el derecho a la independencia } \\
\text { económica y la libertad de emprender una vida personal } \\
\text { autónoma. }\end{array}$ \\
\hline
\end{tabular}

Fuente: Elaboración propia (2021). 
¿qué dicen los manuales de historia sobre la infancia? análisis de textos escolares chilenos

La matriz prevista fue construida en base al análisis del discurso orientado textualmente (Fairclough, 2003; Londoño y Bermúdez, 2013; Van Leeuwen, 2013; Álvarez, 2021), ya que ayuda a evaluar, en perspectiva crítica, los componentes discursivos que configuran y portan significados del mundo social. En esta línea, se utiliza la semiótica por su pertinencia y rigurosidad para analizar los valores culturales dominantes, la representación simbólica de los niños y niñas, la oposición infanteadulto como una cuestión problemática y la marginalidad de la posición de los infantes en las estructuras sociales. Las convenciones relacionadas con la representación basada en una concepción de dependencia, la supresión de los actores sociales, la representación "neutral", la generalización a partir de la asignación de rasgos comunes y la generalización a partir de singulares y plurales masculinos derivan del análisis del discurso orientado textualmente.

Asimismo, la matriz de la tabla 2 se fundamenta en la tercera modalidad discursiva propuesta por Jurjo Torres (1998) para analizar las formas de manifestación del discurso tradicional en los materiales curriculares. Esta modalidad es el sustento teórico de las categorías "etiqueta del discurso de la domesticidad" y "estereotipación basada en la concepción de mayoría de edad", y sirve en esta investigación para examinar los rasgos dominantes en el discurso que ayudan a mantener el paradigma adultocéntrico y detectar las etiquetas que utiliza para disfrazar una realidad difícil de ocultar en el acto comunicativo.

Dichas categorías permiten extraer de los textos escolares las representaciones discursivas de los infantes que han participado en la historia chilena y occidental. Esta selección se llevó a cabo a través del proceso de etiquetamiento-desagregaciónreagregación propuesto por Sayago (2014), pues, en primer lugar, se realizó una búsqueda transversal, siguiendo la unidad de muestreo, registro, recurrencia y codificación abierta de las unidades temáticas elegidas; y, en segundo lugar, a partir de una búsqueda vertical y utilizando la técnica de saturación teórica, se identificaron las evidencias que se examinan en los resultados. 
La perspectiva de la literacidad crítica resulta clave para entender la forma en la que el abuso de poder y las desigualdades entre el mundo adulto e infantil se representan y reproducen en el discurso escrito e iconográfico (Fairclough, 2013; Van Leeuwen, 2014; Pérez, 2016; Van Dijk, 2019; Álvarez, 2021); asimismo, permite criticar las narrativas tradicionales a través de la indagación de los silencios y las exclusiones presentes en los discursos dominantes de los manuales escolares. Siguiendo este enfoque $\mathrm{y}$, a partir de las convenciones previstas en la matriz de análisis, esta investigación busca responder a la siguiente pregunta central: ¿Cuáles son las principales representaciones sobre la infancia que se observan en los textos escolares de Historia, Geografía y Ciencias Sociales? Para lograr este propósito, el análisis discursivo, en una primera instancia, tiene por objetivo responder a las siguientes preguntas planteadas por Tosar (2018): ¿Quién está representado? ¿Qué voces faltan? ¿Quién se beneficia de esto? Estas interrogantes sirven como lineamientos indagatorios para analizar, en una segunda instancia, las representaciones sobre la infancia contenida en los cuatro libros de texto, reflexionar sobre los silencios presentes y evaluar los posibles efectos sociales de los mensajes.

\section{resultados}

Con el fin de responder a la pregunta central de esta investigación, se analizan, a partir de la matriz propuesta, las unidades temáticas mencionadas en la tabla 1. También se adjuntan algunas evidencias que permiten visibilizar de mejor forma la categoría observada.

\section{Manual 1}

\begin{tabular}{|l|}
\hline Texto: Historia, Geografía y Ciencias Sociales $5^{\circ}$ básico \\
\hline Autor: Paulo Flores \\
\hline Editorial: Editorial SM \\
\hline Año: 2019 \\
\hline
\end{tabular}


¿qué dicen los manuales de historia sobre la infancia? análisis de textos escolares chilenos

Nombre de la Unidad: Unidad III. “¿Qué tipo de sociedad se formó durante la Colonia?” (págs. 110-165)

\section{Categorías observadas}

Representación basada en una concepción de dependencia: En el contexto de la sociedad del Chile colonial, el texto escolar presenta a los niños y niñas como actores pasivos y supeditados al hogar paterno, ya que señala textualmente que "al depender económicamente de sus padres, desempeñaban las funciones que estos les designaban, las cuales estaban determinadas por el lugar que ocupaban en la sociedad colonial" (Flores, 2019, p. 134). En esta línea, se representa al infante como un elemento adosado al mundo adulto, pero no desde una lógica de interrelación sino como un simple componente aditivo que está subordinado a dicho estamento, pues se subraya únicamente en los preceptos que sustentan el paternalismo y la dependencia económica del niño.

Representación "neutral": En la infografía, que se adjunta como evidencia 1, prevalece una narrativa descriptiva y mínimamente interpretativa sobre la situación de las mujeres y de los niños según el grupo social al cual pertenecían.

Generalización a partir de la asignación de rasgos comunes: En la evidencia 1 se evoca a constantes generalizaciones y sesgos porque representa el maltrato infantil como una cuestión exclusiva de los esclavos, expone el rol de "jefas de hogar" como un rasgo propio de los mestizos y plasma el papel de "buena esposa y madre" como un denominativo que solo aplica para el caso de la aristocracia.

Generalización a partir de singulares y plurales masculinos: Se utiliza un lenguaje poco inclusivo, pues se emplean las etiquetas del singular "niño" y del plural "niños" para involucrar también a las niñas; no obstante, dichos denominativos, que parecen inofensivos a simple vista, contribuyen a la marginación de la/s niña/s en la sociedad colonial y de su respectiva relevancia en el devenir histórico.

Etiqueta del discurso de la domesticidad: Se utiliza para justificar que la vida del infante se restringía únicamente al ámbito doméstico, que, según el texto, "estaba bajo el dominio de las mujeres" (Flores, 2019, p. 138).

\section{Evidencia 1}
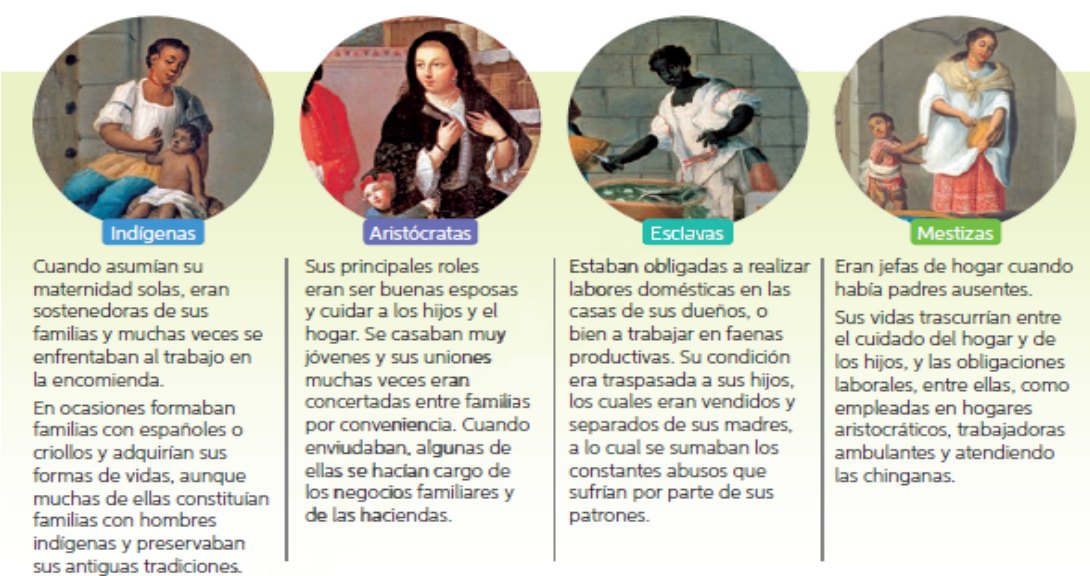

Estaban obligadas a realizar | Eran jefas de hogar cuando labores domésticas en las había padres ausentes. $\begin{array}{lll}\text { casas de sus dueños, o } & \text { Sus vidas trascurrian entre } \\ \text { bien a trabajar en faenas } & \text { el cuidado del hogar y de }\end{array}$ $\begin{array}{lll}\text { bien a trabajar en faenas } & \text { el cuidado del hogar y de } \\ \text { productivas. Su condición } & \text { los hiios, y las obligaciones }\end{array}$ era traspasada a sus hijos, laborales, entre ellas, come los cuales eran vendidos y laborales, entre ellas, com separados de sus madres, a lo cual se sumaban los, aristocraticos, trabajadoras constantes abusos que sufrian por parte de sus indigenas y preservaba sus antiguas tradiciones

Fuente: Flores, 2019, p. 134. 


\section{Manual 2}

Texto: Historia, Geografía y Ciencias Sociales $7^{\circ}$ básico

Autor: Gonzalo Beltrán, Francisco Fuentes, Pedro Panza y Carolina Valdés

Editorial: Editorial SM

Año: 2019

Nombre de la Unidad: Unidad II. “¿En qué ámbitos de las sociedades actuales se aprecia la influencia de las civilizaciones clásicas?" (pp. 68-119)

\section{Categorías observadas}

Representación basada en una concepción de dependencia: En el análisis de la familia aristocrática romana, se pone énfasis en la idea de que la niñez es una condición de dependencia e inferioridad que invisibiliza la participación del infante como actor social y que contribuye a su representación como un sujeto periférico, sin autoridad y sin poder de transformación. Esta narrativa sirve para legitimar el paternalismo familiar romano, pues el texto escolar sostiene que "tanto las mujeres, como los niños y los esclavos estaban bajo la tutela de sus respectivos pater familias (hombres cabeza de familia)" (Beltrán, Fuentes, Panza y Valdés, 2019, p. 92).

Supresión de los actores sociales: En el contexto de la Antigua Grecia, el libro de texto excluye la acción de los niños y niñas, ya que se centra solamente en describir las hazañas políticas realizadas por hombres adultos para contribuir al desarrollo de la democracia ateniense. Al respecto, destaca la evidencia 2 porque releva, en forma nominada e individual, el protagonismo de los grandes reformadores de Atenas y sus respectivos aportes en la conformación democrática de dicha ciudad durante los siglos VII y VI a. C.

Generalización a partir de singulares y plurales masculinos: Se emplea un lenguaje poco inclusivo, pues se usan las etiquetas del singular "niño" y del plural "niños" para incorporar también a las niñas; sin embargo, igualmente dichos términos inducen en forma explícita e implícita a la exclusión de la/s niña/as en las sociedades griega y romana.

Estereotipación basada en la concepción de "mayoría de edad": Se utiliza para definir quiénes son o no ciudadanos en la democracia ateniense, pues el manual argumenta que solo "los hombres libres mayores de 20 años eran considerados ciudadanos y podían disfrutar de los derechos que esta condición otorgaba, quedando excluida la mayor parte de la población, prácticamente tres cuartos del total: todas las mujeres, los metecos (extranjeros) y los esclavos" (Beltrán, Fuentes, Panza y Valdés, 2019, p. 80). Por una parte, esta interpretación presenta la edad como un criterio que conlleva un sistema de poder que jerarquiza y ordena un conjunto de derechos o prohibiciones en función de las relaciones personales, las estructuras institucionales, las prácticas sociales y las leyes que dominaban la democracia ateniense. Por otra parte, reduce, desde los paradigmas androcéntrico y adultocéntrico, el concepto de ciudadanía a una simple relación política entre el varónciudadano y la polis. 


\section{Evidencia 2}

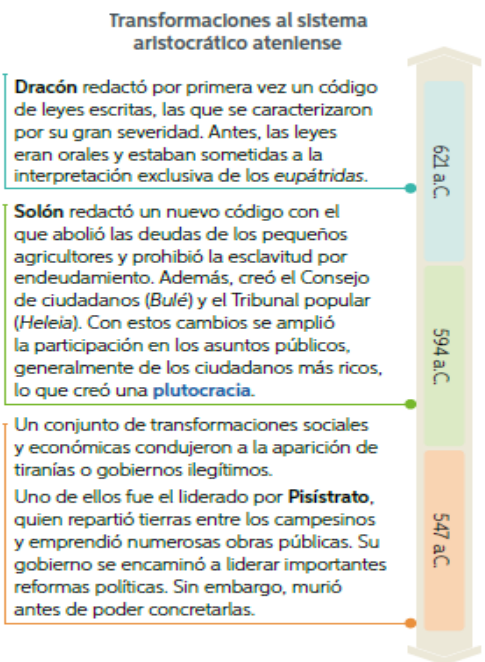

Fuente: Beltrán, Fuentes, Panza y Valdés, 2019, p. 76.

\section{Manual 3}

\begin{tabular}{|l|}
\hline Texto: Historia, Geografía y Ciencias Sociales $1^{\circ}$ medio \\
\hline Autor: José Morales, Sergio Pastene, Carolina Santelices y Sebastián Quintana \\
\hline Editorial: Santillana \\
\hline Año: 2016 \\
\hline
\end{tabular}

Nombre de la Unidad: Unidad III. "El progreso indefinido y sus contradicciones" (pp. 132-191)

\section{Categorías observadas}

Representación basada en una concepción de dependencia: En el contexto de la sociedad europea de la segunda mitad del siglo XIX, se representa a todos los niños, sin importar su condición social o su composición familiar, como sujetos proveedores que están subordinados, junto a las mujeres, al hogar paterno, pues se señala que "en el caso de los niños, no era obligación la asistencia a la escuela, y su trabajo, al igual que el de las mujeres, era fundamental para sus familias" (Morales, Pastene, Santelices y Quintana, 2016, p. 156).

Representación "neutral": El texto escolar pretende exponer, a través de una serie de recursos visuales, una lectura "imparcial" sobre el trabajo infantil que existió entre finales del siglo XIX y comienzos del siglo XX. Al respecto, destaca la evidencia 3 porque cuenta con un encabezado escueto, descriptivo y "neutral" sobre la fotografía "Niños que trabajan en un molino en Macon, Georgia" de Lewis Hine. Dicha referencia no aporta información valiosa que permita reflexionar, en forma crítica y sistemática, sobre la denuncia social que solía plasmar el fotógrafo estadounidense a través de sus imágenes, el rol que tuvieron los infantes 
fotografiados como agentes sociales o acerca de los rasgos que caracterizaban el trabajo infantil en aquella época.

Generalización a partir de singulares y plurales masculinos: Se emplea un lenguaje poco inclusivo, pues se utilizan las etiquetas del singular "niño" y del plural "niños" para integrar también a las niñas; no obstante, dichos denominativos, de igual forma, contribuyen a la invisibilización de la/s niña/s en la sociedad europea que se extendió entre los años 1800 y 1910.

\section{Evidencia 3}

\section{Recurso 36 (fuente iconográfica)}

En esta fotografía puedes observar una de las formas de trabajo infantil que existieron en el siglo XIX y comienzos del XX.

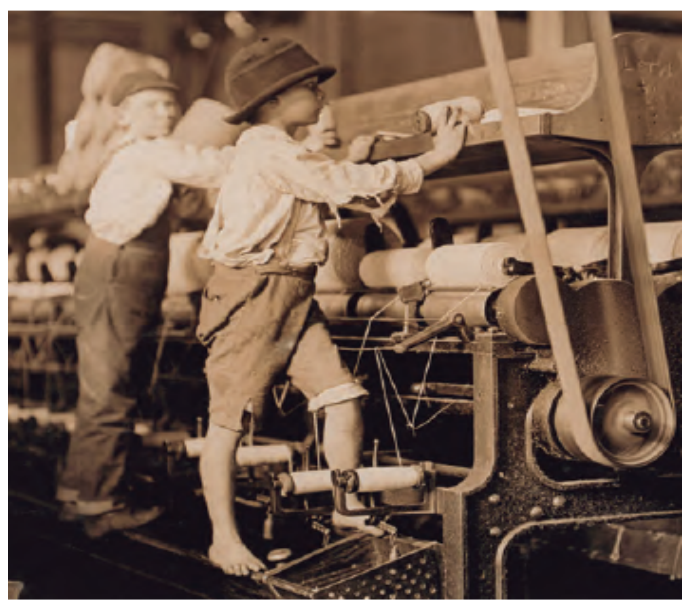

Hine, L. (1909). Niños que trabajan en un molino en Macon, Giorgia. Biblioteca del Congreso de Estados Unidos.

Fuente: Morales, Pastene, Santelices y Quintana, 2016, p. 156.

\section{Manual 4}

\begin{tabular}{|l|}
\hline Texto: Historia, Geografía y Ciencias Sociales $2^{\circ}$ medio \\
\hline Autor: Sofía Honeyman, Camila Silva, Sebastián Quintana y Carolina Santelices \\
\hline Editorial: Santillana \\
\hline Año: 2017 \\
\hline
\end{tabular}




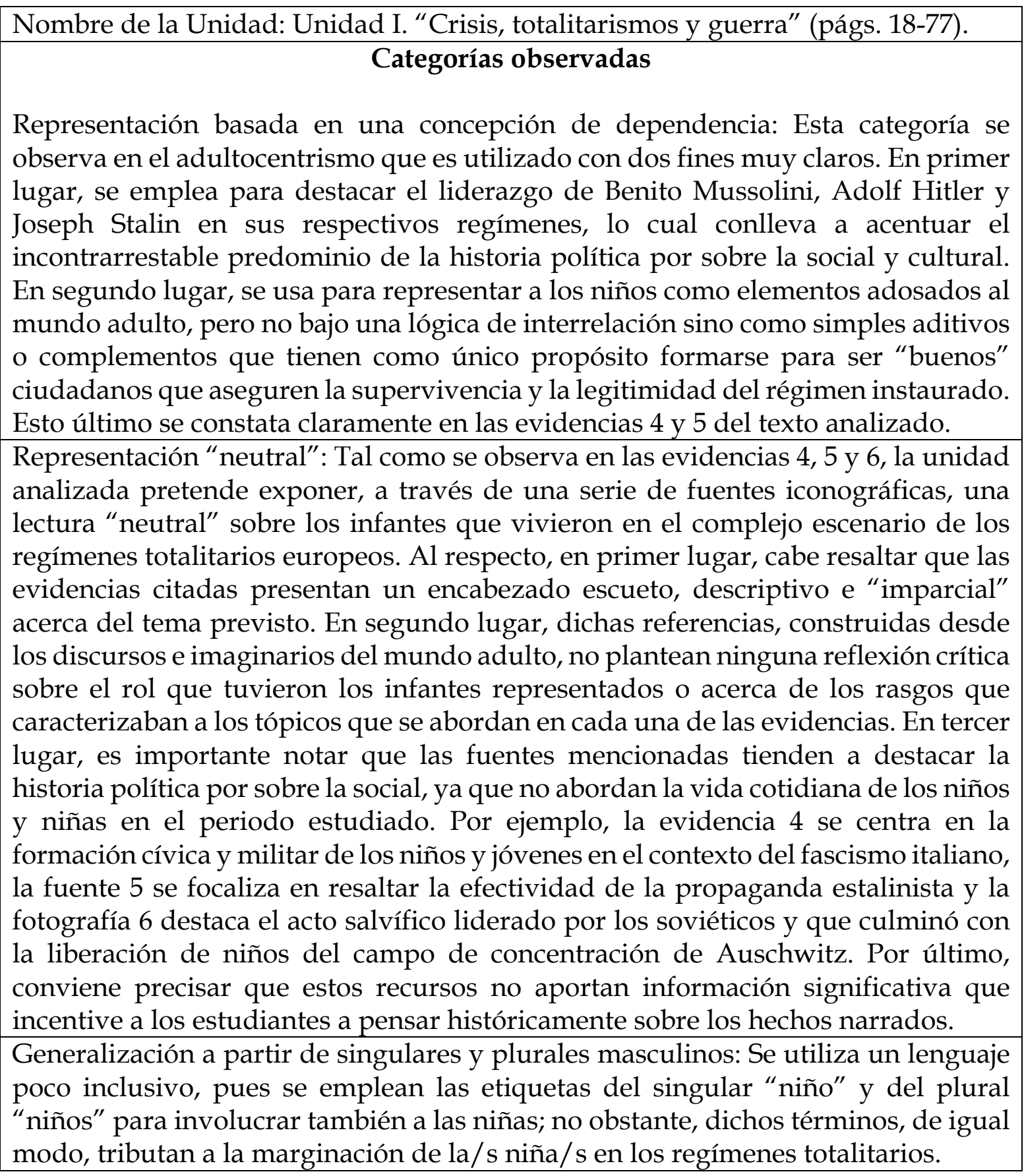




\section{Evidencia 4}

Recurso 32 (fuente iconográfica)

En la Italia fascista, los niños y jóvenes entre los 4 y los 18 años debían formar parte de organizaciones juveniles controladas por el partido, como la Obra Nacional Balilla. Se intentaba forjar al "italiano nuevo"en las virtudes militares de la disciplina y la obediencia.

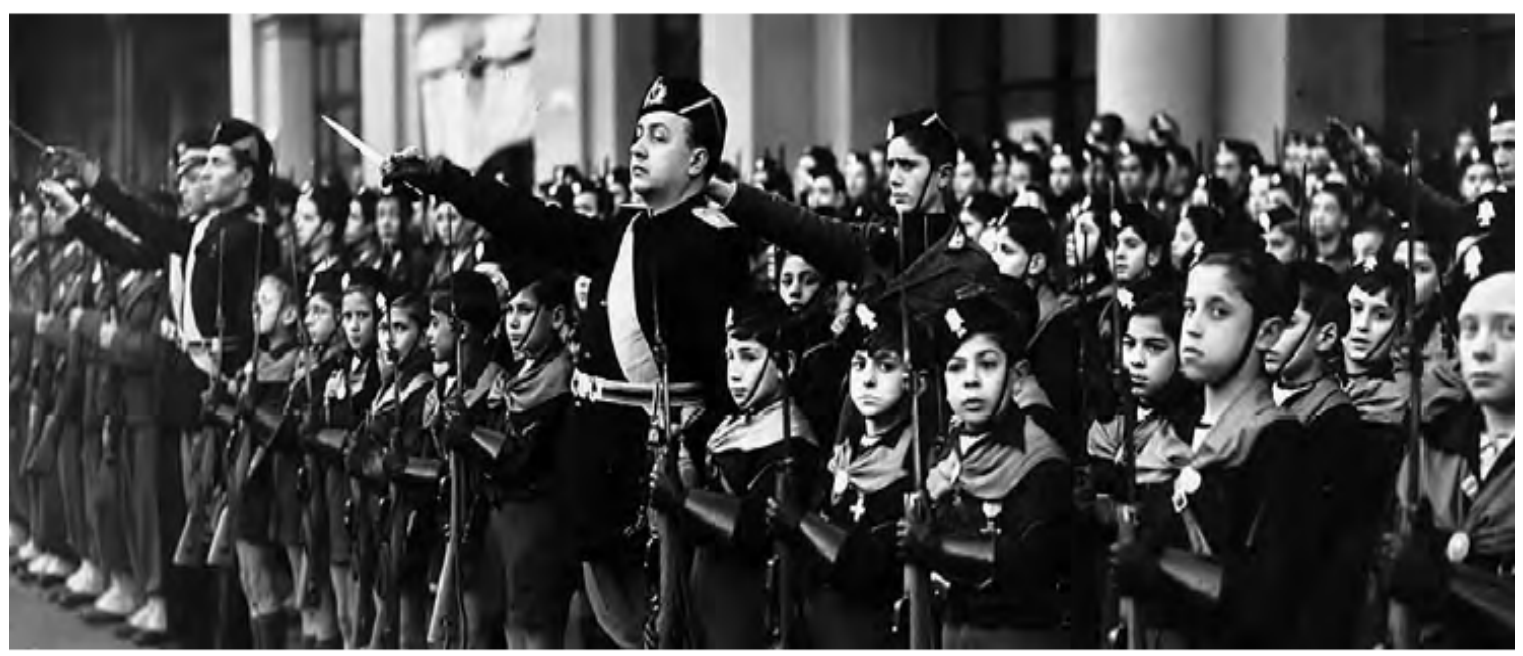

Ninos miembros de la Obra Nacional Balilla. (S. i.).

Fuente: Honeyman, Silva, Quintana y Santelices, 2017, p. 41.

\section{Evidencia 5}

Recurso 39 (fuente iconográfica)

En la época estalinista, los carteles de propaganda fueron utilizados para ensalzar la figura del líder.

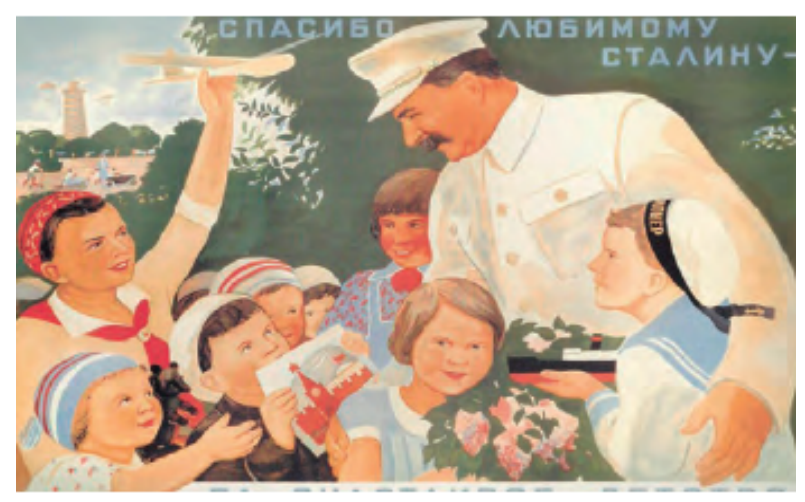

¡Gracias al querido Stalin por nuestra infancia feliz! (S. i.).

Fuente: Honeyman, Silva, Quintana y Santelices, 2017, p. 44.

\section{Evidencia 6}

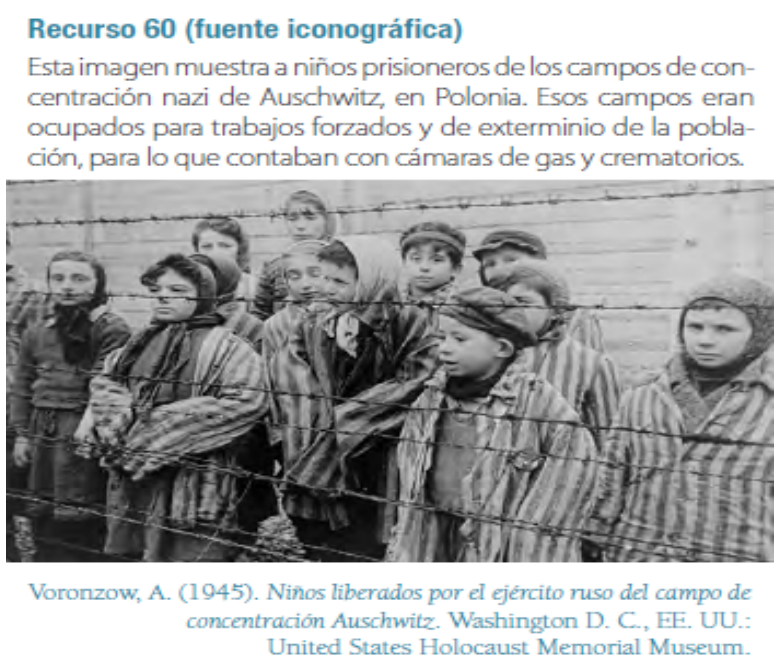

Fuente: Honeyman, Silva, Quintana y Santelices, 2017, p. 56.

\section{discusión}

Las unidades analizadas, al igual que los estudios de DeMause (1974) y de Ariès (1987), representan a los infantes desde los discursos e imaginarios construidos por los 
¿qué dicen los manuales de historia sobre la infancia? análisis de textos escolares chilenos

hombres adultos. Esta narrativa, como sostienen Gonzaga, Santiago y Goulart (2018), ignora la capacidad de los niños y niñas para interactuar, dialogar o resistir al orden impuesto por el mundo adulto, pues, al considerarse únicamente el paradigma adultocéntrico en los manuales escolares, se corre el riesgo de concebir a los/as niños/as como agentes sociales ausentes en la historia y de convertir a estos/as en simples receptores/as de un sistema educativo pensado desde la idiosincrasia oficial.

Este problema de marginación de la infancia se observa en los libros de texto a través de todas las convenciones consignadas en la tabla 2. Con respecto a la representación basada en una concepción de dependencia, es importante señalar que esta categoría se constata en las cuatro unidades analizadas porque prevalece la idea de que la niñez es una condición de dependencia y sumisión que conlleva un trato de inferioridad corporal o de inactividad económica y sexual. Dicha representación se suele dar en evidencias que explicitan la dependencia económica del infante, tal como ocurre con una de la unidad “QQué tipo de sociedad se formó durante la Colonia?” del manual 1 que precisa, desde una óptica paternalista, que los niños "al depender económicamente de sus padres, desempeñaban las funciones que estos les designaban, las cuales estaban determinadas por el lugar que ocupaban en la sociedad colonial" (Flores, 2019, p. 134).

La representación basada en una concepción de dependencia también se aprecia en el uso del adultocentrismo utilizado para subrayar la historia política protagonizada por hombres adultos pertenecientes a la clase dirigente. Destaca el caso del manual 4, que analiza los roles de Musolinni, Hitler y Stalin en sus respectivos regímenes totalitarios, pues en las evidencias 4 y 5 se representan a los niños como elementos adosados al mundo adulto que tienen como único objetivo de vida el de formarse para ser "buenos" ciudadanos que garanticen la preservación del régimen instaurado por dichos líderes políticos. Este rasgo que pone énfasis en la historia política también se observa en la supresión de los/as niños/as en la historia, puesto que en la mayor parte de las unidades examinadas se omite su participación y se enaltece únicamente el rol histórico del mundo adulto. Al respecto, destaca la evidencia 2 porque releva, en forma 
nominada e individual, el protagonismo de los grandes reformadores de Atenas y sus respectivos aportes en la conformación democrática de dicha ciudad durante los siglos VII y VI a. C.

Dicha interpretación, vinculada claramente a un enfoque histórico tradicional, ha reducido el estudio de tales temáticas a un simple relato descriptivo y cronológico que, por una parte, expone una visión patriarcal y androcéntrica de la historia que pretende enaltecer el papel de los hombres insignes en la vida pública y restringir la actuación femenina al ámbito doméstico; y, por otra, busca ignorar la alteridad de los "otros" porque el discurso histórico no se presenta desde las perspectivas de las mujeres o de los niños. Siguiendo a Fontana (2011), dicha lectura relega a los grupos subalternos y sus problemas al margen de los estudios de historia, como si fuesen una parte marginal de la sociedad. Este hecho demuestra que los avances observados en la historia social y cultural no se han considerado en lo absoluto en la narrativa histórica escolar, lo cual revela una profunda desconexión entre el saber histórico y la historia enseñada.

La representación "neutral", siguiendo a Álvarez (2021), se visualiza en la presencia de encabezados escuetos, descriptivos e "imparciales" que suelen acompañar a diversas fuentes iconográficas. Esto se observa principalmente en las evidencias 3, 4, 5 y 6 , pues en sus respectivos encabezados no se precisa una contextualización histórica detallada sobre el recurso expuesto, ni se plantea una reflexión crítica que motive al alumnado a investigar o a pensar históricamente sobre la problemática tratada. Esta forma de representación distancia a los niños y niñas de los procesos históricos porque utiliza un elevado nivel de abstracción para exponerlos/as como figuras que están al margen de los acontecimientos. A esto se debe sumar que las evidencias mencionadas se ubican en apéndices o recuadros apartados del discurso central, lo que, según Fernández (2010), puede aumentar el riesgo de que el lector no considere a los actores sociales allí representados o no les asigne la importancia requerida, o bien que no sea capaz de relacionar su relevancia histórica con los procesos históricos abordados en el resto de la unidad. 
¿qué dicen los manuales de historia sobre la infancia? análisis de textos escolares chilenos

La generalización a partir de la asignación de rasgos comunes se observa concretamente en tres alusiones que hace el texto escolar 1 sobre los infantes y su respectivo contexto familiar porque, al referirse a la evidencia 1, presenta el maltrato infantil, el rol de las "jefas de hogar" y el concepto de "buena esposa y madre" como cuestiones exclusivas de una determinada clase social en el contexto de la sociedad del Chile colonial, ignorando, de este modo, que tales problemáticas son transversales en la sociedad y que son independientes de la clase social, de las creencias o del origen étnico. De igual modo, siguiendo a Nash (2020), es importante señalar que esta generalización va acompañada por la etiqueta del discurso de la domesticidad para argumentar que la vida de los/as niños/as se circunscribía únicamente al ámbito privado del hogar.

La generalización a partir de singulares y plurales masculinos se manifiesta en todas las unidades analizadas porque se fundamentan en un lenguaje poco inclusivo, pues emplean las etiquetas del singular "niño" y del plural "niños" para incorporar también a las niñas; no obstante, dichos términos, que parecen lógicos e inofensivos a simple vista, contribuyen a invisibilizar la relevancia histórica de la/s niña/s en los hechos del pasado. Esta marginación, como sostienen la historiadora Mary Nash (2002) y la socióloga Barrie Thorne (2012), también se observa en los estudios más innovadores sobre la historia de las mujeres porque tienden a poner énfasis en las figuras femeninas adultas y en el contexto de blancura de la civilización occidental, cuyos principios refuerzan y perpetúan el destierro de las niñas en el devenir histórico.

En cuanto a la etiqueta del discurso de la domesticidad, es importante notar que esta, siguiendo a Nash (2020), se utiliza para justificar que la vida del infante se restringía únicamente al ámbito doméstico. Al respecto, destaca el caso del manual 1 que señala explícitamente que los niños y niñas del Chile colonial "estaban bajo el dominio de las mujeres" (Flores, 2019, p. 138), puesto que dicha referencia naturaliza el dominio del sistema patriarcal donde las mujeres se consagran a la vida privada del hogar, limitándose a la realización de las tareas domésticas y a la crianza de los niños, y donde los hombres sobresalen en la vida pública al asumir roles de liderazgo político, 
privilegio social, autoridad moral y control de la propiedad (Scott, 1990; Nicholson, 1992; Álvarez, 2021).

La estereotipación basada en la concepción de "mayoría de edad" se emplea para definir quiénes son o no adultos, cuyo parámetro también ha servido para fijar el inicio del status de ciudadano que podían alcanzar exclusivamente los hombres en un contexto histórico dado. Esto se constata en el manual 2, donde se señala que solo los hombres libres mayores de 20 años pueden ser ciudadanos dentro de la democracia ateniense y se usa el criterio de edad para justificar la ausencia de derechos políticos en los niños y jóvenes. Esta evidencia, además de corroborar el rasgo previsto, centra el análisis de la niñez en los estratos altos y libres de la sociedad ateniense, ignorando, de esta manera, las diversidades existentes entre los diferentes grupos sociales con respecto a las distintas concepciones que tenían sobre la infancia. La misma convención discursiva también se aprecia en la evidencia 4, en la cual se sostiene que los niños y jóvenes de entre 4 y 18 años se deben formar en las virtudes militares para forjar al "italiano nuevo" dentro de la lógica fascista. Esta representación basada en el criterio de edad, siguiendo a Sosenski (2015), privilegia un enfoque biológico y psicológico para definir la niñez o adolescencia, razón por la cual rechaza directamente una perspectiva fenomenológica que permita tratar dichos conceptos como construcciones socioculturales que dependen del contexto histórico en el cual se insertan.

En el ámbito previsto, conviene notar que los manuales examinados presentan la infancia como una etapa de la vida donde los niños deben instruirse para que cuando sean mayores de edad logren convertirse en "buenos" ciudadanos capaces de garantizar la continuidad del orden establecido. Así, como afirman Sosenski y Jackson (2013), ha primado la idea del niño ciudadano que permitió a las sociedades proyectar una imagen utópica de su futuro, cuyo precepto es medido desde la óptica del poder político o representado bajo la postura de los padres de los infantes. Este planteamiento anula la posibilidad de que los niños y niñas actuaban según sus circunstancias particulares o de acuerdo con las barreras sociales que los limitaban y, siguiendo a Maldonado y Andrade (2017), invalida las facultades de los niños y niñas para 
¿qué dicen los manuales de historia sobre la infancia? análisis de textos escolares chilenos

formular ideas, generar teorías, liderar procesos sociales, crear objetos, construir argumentaciones y emitir juicios razonados. Como indica Pavez (2012), se desarrolla y perpetua así un estereotipo generacional que sitúa a los infantes bajo la potestad y superioridad de la persona adulta, que, desde la lógica del pensamiento occidental, se considera racional y civilizada.

Esta lectura hegemónica delineada desde el curriculum escolar es reduccionista y errada porque ignora el hecho de que los/as niños/as son ciudadanos/as desde que nacen y prosiguen con su desarrollo posterior, pues a lo largo de toda su vida tienen la capacidad de interactuar con su entorno para manifestar sus necesidades, emociones y opiniones y participar en decisiones que pueden comprometer su bienestar dentro de su contexto familiar o social. Por esta razón, no se puede simplificar el concepto de ciudadanía desde un enfoque cívico basado en los paradigmas androcéntrico y adultocéntrico, ya que, como afirma Álvarez (2020), el surgimiento de las perspectivas de género, de la interculturalidad y de la infancia exige a los productores de textos escolares y a los profesores de historia cambiar radicalmente sus discursos y prácticas convencionales por unas más plurales y constructivistas que ayuden a forjar una enseñanza de la especialidad más activa e innovadora.

Adicionalmente, hay que considerar que los criterios de dependencia económica y de edad utilizados en las representaciones evidenciadas, como argumenta Sosenski (2015), no aplicaban para la mayor parte de las sociedades del pasado, ya que no existe una definición única de niño y tampoco es posible definir la infancia en función de la edad, o en términos de dependencia, de inocencia, de sexualidad inactiva o de alejamiento del mundo laboral. En esta línea, cabe destacar que el concepto de niñez solo adquiere validez y significado en el propio contexto histórico en el cual se desarrolla. Así, como señalan Pagès y Villalón (2013), la infancia no se puede pensar como una categoría homogénea, pues, aunque tenga aspectos comunes en todo el mundo, depende de diversas variables como la clase social, la etnia o la religión.

También, resulta clave mencionar que la representación de la infancia como una condición de dependencia y sumisión conlleva, de forma explícita e implícita, la idea 
de que los niños fueron, son y serán víctimas del mundo adulto, cuya posición puede contribuir a fortalecer su victimización social y a desconocer su capacidad para liderar el cambio social en el mundo que les rodea. Para evitar este problema, es necesario que el tratamiento de la niñez en los textos escolares e investigaciones históricas sea relacional y holístico, ya que el significado del trabajo infantil, del consumo, de la escolarización o de cualquier otra experiencia de los/as niños/as en el pasado solo pueden comprenderse a través de un estudio sistemático y riguroso sobre los fenómenos políticos, ideológicos, culturales y socioeconómicos que inciden en tales procesos y sus respectivas formas de relación con los conflictos y contradicciones imperantes en la sociedad analizada. De esta manera, enseñar la historia de la niñez permite poner en diálogo las perspectivas infantiles con las adultas y advertir la forma en que el mundo adulto se ha relacionado con los niños y niñas.

Por último, conviene notar que no figura ningún apartado dedicado a resignificar el rol de los niños y niñas en un determinado periodo histórico. Por este motivo, la marginación parcial o total de los niños y niñas en los manuales de Historia, Geografía y Ciencias Sociales promueve, con gran fuerza, un relato basado en el predominio de la historia adultocéntrica que va quedando en el imaginario colectivo como una verdad establecida. Esto, más allá de la injusticia que reviste para los infantes, es nefasto para las sociedades, pues la narrativa histórica tradicional, al excluir la perspectiva de los niños y niñas, solo representa una memoria histórica incompleta y parcializada que solo reproduce la voz de grupos hegemónicos que legitiman ciertos referentes ideológicos.

\section{conclusión}

La investigación desarrollada demuestra que las representaciones sobre la infancia presentes en las unidades analizadas son concebidas desde el discurso adultocéntrico, ya que en todas ellas se invisibiliza la niñez o se trata como una condición de dependencia o subordinación del mundo adulto. Esto se observa explícitamente en el hecho de que no existe ningún apartado dedicado a reivindicar el 
¿qué dicen los manuales de historia sobre la infancia? análisis de textos escolares chilenos

rol histórico de los niños y niñas, en la representación "neutral" de estos/as en los encabezados de las evidencias 3, 4, 5 y 6 y en el empleo del criterio de edad como una condición sine qua non para establecer quienes son adultos o no en un determinado contexto y espacio histórico.

El adultocentrismo se constata además en la representación de los niños y niñas desde una concepción de dependencia que otorga un trato de inactividad económica y sexual a la infancia y que subraya la historia política protagonizada por hombres adultos ilustres. Esta representación sobresale fundamentalmente en el texto escolar 1, donde se resaltan las contribuciones de los forjadores de la democracia ateniense, y en el manual 4, que aborda los liderazgos políticos de Hitler, Musolinni y Stalin en sus respectivos sistemas totalitarios.

Asimismo, es importante notar que los libros de historia analizados usan distintos tipos de generalización para referirse a la situación de los infantes en diferentes contextos históricos, destacándose el caso de la evidencia 1 porque presenta el rol de las "jefas de hogar", el maltrato infantil y el estereotipo de "buena esposa y madre" como aspectos exclusivos de una clase social específica del Chile colonial, ignorando así el hecho de que tales disyuntivas son trasversales en todos los sectores de la sociedad.

El encubrimiento del niño realizado en los textos escolares de Historia, Geografía y Ciencias Sociales ha buscado construir e imponer un modelo de sociedad occidental, donde las distintas categorías vistas sobre la invisibilización del infante se presentan como un rasgo naturalizado y extendido en el curriculum de la asignatura. De tal forma, los manuales analizados responden a los lineamientos pedagógicos tradicionales de las editoriales SM y Santillana, ya que las evidencias analizadas, además de reproducir y legitimar el modelo adultocéntrico en el sistema educativo, corroboran que son altamente contraproducentes con los nuevos lineamientos de la enseñanza de la historia que buscan desarrollar el pensamiento histórico en el alumnado, puesto que no permiten comprender las temáticas estudiadas de forma controvertida o desde la postura de perspectivas críticas que reivindiquen las voces 
silenciadas de los niños y niñas que participaron activamente en la construcción de la historia de la humanidad.

Por tal motivo, el libro de texto, entendido como un artefacto cultural, se fundamenta en verdades históricas universales y sesgadas que configuran una perspectiva histórica tradicional. Esto puede contribuir a garantizar la posición dominante del mundo adulto en la sociedad y a potenciar la legitimación de consensos en torno a creencias que no permiten valorar el rol de los niños y niñas en la historia.

Para evitar dicho riesgo, es importante considerar dos lineamientos claves para empezar a avanzar en la incorporación y en la resignificación de la infancia en la historia enseñada. En primer lugar, resulta indispensable democratizar el curriculum para no seguir replicando el paradigma adultocéntrico en los textos escolares y contribuir a privilegiar un enfoque histórico crítico y reflexivo que valore a los/as niños/as como actores sociales. En segundo lugar, desde el punto de vista del profesorado, es importante presentar los contenidos referidos a los infantes a través de fuentes atractivas y rigurosas para el estudiante. Este trabajo debe ir acompañado con la problematización de las temáticas del curriculum y con la incorporación de contenidos derivados de controversias históricas actuales, ya que ambos aspectos suelen aumentar significativamente el interés del estudiantado por la asignatura de historia.

Las dos medidas, sin duda alguna, pueden facilitar y mejorar el proceso de empatía histórica de los niños y niñas porque les permite comprender que las personas de su edad son actores sociales relevantes en la historia y que no son un componente aditivo o dependiente del mundo adulto. En esta línea, el presente trabajo hace un aporte significativo al campo de estudio previsto, pues es el primero que se preocupa de establecer una primera aproximación sobre la representación de la infancia en los textos escolares de Historia, Geografía y Ciencias Sociales de Chile y, además, porque deja la puerta abierta para que nuevas investigaciones a nivel nacional e internacional puedan seguir contribuyendo al estudio de la temática. 
¿qué dicen los manuales de historia sobre la infancia? análisis de textos escolares chilenos

\section{referencias bibliográficas}

Álvarez, H. (2020). Enseñar historia a través de la perspectiva de género. Evaluación de una propuesta de innovación. Mendive, 18(3), 599-617.

Álvarez, H. (2021). Género y textos escolares: Representaciones de las mujeres chilenas de la primera mitad del siglo XX. Revista Conhecimento Online, (1), 153-176. https:// doi.org/10.25112/rco.v1i0.2395

Ariès, P. (1978). El niño y la historia familiar en el Antiguo Régimen. Madrid: Taurus.

Bases Curriculares de $7^{\circ}$ básico a $2^{\circ}$ Medio (2016). Documento curricular. Santiago de Chile: Ministerio de Educación.

Bourdieu, P. (2008). Capital cultural, escuela y espacio social. México: Siglo XXI.

Canales, P., Fernández, M. y Rubio, A. (2018). Textos escolares de historia: La reproducción del racismo contra los pueblos indígenas en Chile. Revista Austral de Ciencias Sociales, (34), 153-167. https:/ / doi.org/10.4206/rev.austral.cienc.soc.2018.n34-10

Ciafardo, E. (1992). Los niños en la ciudad de Buenos Aires, 1890-1910. Buenos Aires: Biblioteca Política.

DeMause, Ll. (1974). Historia de la infancia. Madrid: Alianza Editorial.

Fairclough, N. (2003). Representations of social events. In: N. Fairclough (coord.). Analysing Discourse. Textual analysis for social research (pp. 134-155). New York: Routledge.

Fairclough, N. (2013). Language and power. New York: Routledge.

Fernández, M. (2010). Las mujeres en el discurso pedagógico de la historia. Exclusiones, silencios y olvidos. Universum, 25(1), 84-99. http://dx.doi.org/10.4067/S071823762010000100007

Fontana, J. (2011). Por el bien del imperio. Una historia del mundo desde 1945. Barcelona: Pasado y Presente.

Espinoza, J. (2012). El texto escolar como artefacto cultural: Estudio sobre representación de la identidad nacional en textos escolares de Historia durante la dictadura civil-militar en Chile (1973-1990). Paulo Freire. Revista de Pedagogía Crítica, 11(11), 69-83. https://doi.org/10.25074/07195532.11.446

Gazmuri, R. (2017). Ideologías curriculares en el debate y negociación del currículum chileno de Historia, Geografía y Ciencias Sociales. Estudios Pedagógicos, 43(1), 157-169. http://dx.doi.org/10.4067/S0718-07052017000100010

Gonzaga, E., Santiago, F. y Goulart, A. (2018). As culturas infantis interrogam a formação docente: Tessituras para a construção de pedagogias descolonizadoras. Revista Linhas, 19(39), 80-102.

Jara, I. (2018). Adultocentrismo y género como formas negadoras de la cultura infantil. Revista Saberes Educativos, (1), 47-67. 10.5354/2452-5014.2018.51604

Maldonado, E. y Andrade, P. (2017). Pedagogía y Espacio Arquitectónico: Escenarios para crear, jugar e imaginar. Santiago de Chile: Ediciones Junji.

Marín, O. (2020). La representación de las mujeres prehistóricas en los textos escolares de Historia, Geografía y Ciencias Sociales en Chile (2010-2018). Estudios Pedagógicos, 46(1), 7-31. https:/ / doi.org/10.4067/S0718-07052020000100007

Marolla, J. (2019). ¿Qué nos dicen los libros de texto sobre la interculturalidad? Análisis sobre los materiales chilenos. Revista de Investigación en Didáctica de las Ciencias Sociales, (4), 110-127.

Marolla, J. y Solís, C. (2021). América Latina en el currículo chileno de Historia: Análisis desde la literacidad crítica. Revista Colombiana de Educación, 1(82), 61-81. https://doi.org/10.17227/rce.num82-10499 
Morales, S. (2020). Movimientos sociales y participación política de niñas y niños. Crítica y Resistencias. Revista de Conflictos Sociales Latinoamericanos, (10), 22-38.

Nash, M. (2002). Los nuevos sujetos históricos: Perspectivas de fin de siglo. Género, identidades y nuevos sujetos históricos. En: M. Romeo e I. Saz (eds.). El siglo XX. Historiografía e historia (pp. 85-100). Valencia: PUV.

Nash, M. (2020). Turismo, género y neocolonialismo: La sueca y el donjuán y la erosión de arquetipos culturas franquistas en los 60. Historia Social, (96), 41-62.

Nicholson, L. (1992). Hacia un método para comprender el género. En: C. Ramos (comp.). Género e historia, la historiografía sobre la mujer (pp. 142-180). México: Instituto Mora.

Lester, L. y Labraña, C. (2018). Siete tesis en torno al texto escolar como artefacto cultural. Revista Brasileira de Educação, (23), 1-19. https:/ / doi.org/10.1590/S1413-24782018230070

Londoño, D. y Bermúdez, H. (2013). Tres enfoques sobre los estudios críticos del discurso en el examen de la dominación. Palabra Clave, 16(2), 491-519.

Ortega, D. y Pagès, J. (2017). Literacidad crítica, invisibilidad social y género en la formación del profesorado de Educación Primaria. Revista de Investigación en Didáctica de las Ciencias Sociales, (1), 102-117.

Osta, M. y Espiga, S. (2017). La infancia sin historia. Páginas de Educación, 10(2), 111-126.

Pagès, J. y Villalón, G. (2013). Los niños y las niñas en la historia y en los textos históricos escolares. Analecta Calasanctiana, (109), 29-66.

Pagès, J., Villalón, G. y Zamorano, A. (2017). Enseñanza de la historia y diversidad étnica: Los casos chileno y español. Educação $\mathcal{E}$ Realidade, 42(1), 161-182. https:/ / doi.org/10.1590/2175-623661186

Pavez, I. (2012). Sociología de la infancia: Las niñas y los niños como actores sociales. Revista de Sociología, (27), 81-102.

Pérez, C (2016). La representación visual del movimiento estudiantil chileno en la prensa establecida y alternativa nacional: Un análisis multimodal. Revista Austral de Ciencias Sociales, (30), 5-26.

Pollock, L. (1990). Los niños olvidados. Relaciones entre padres e hijos de 1500 a 1900. México: Fondo de Cultura Económica.

Programa de Estudio de Historia, Geografía y Ciencias Sociales de $6^{\circ}$ básico (2018). Documento curricular. Santiago de Chile: Ministerio de Educación.

Rojas, J. (2016). Historia de la infancia en el Chile Republicano, 1810-2010. Santiago: Ediciones de la Junji.

Rubiera, Carla (2018). Las edades vulnerables: Infancia y vejez en la Antigüedad. Gijón: Editorial TREA.

Salinas, R. (2001). La historia de la infancia, una historia por hacer. Revista de Historia Social y de las Mentalidades, (5), 11-30.

Scott, J. (1990). El género, una categoría útil para el análisis histórico. En: J. Amelang y M. Nash (comps.). Historia y género. Las mujeres en la Europa moderna y contemporánea (pp. 23-56). Valencia: Alfons el Magnànim.

Sosenski, S. y Jackson, E. (2013). Nuevas miradas a la historia de la infancia en América Latina: Entre prácticas y representaciones. México: Instituto de Investigaciones Históricas de la Universidad Nacional Autónoma de México.

Sosenski, S. (2015). Enseñar historia de la infancia a los niños y las niñas: ¿para qué?. Revista Tempo e Argumento, 7(14), 132-154. https:/ / doi.org/10.5965/2175180307142015132

Stone, L. (1990). Familia, sexo y matrimonio en Inglaterra, 1500-1800. México: Fondo de Cultura Económica. 
¿qué dicen los manuales de historia sobre la infancia? análisis de textos escolares chilenos

Thorne, B. (2012). Re-visioning women and social change: Where are the children? In: H. Morrison (ed.). The global history of childhood reader (pp. 21-36). New York: Routledge.

Torres, J. (1998). El currículum oculto. Madrid: Morata.

Tosar, B. (2018). Literacidad crítica y enseñanza de las Ciencias Sociales en primaria: Profe, las bolsas de plástico no son medusas. Revista de Investigación en Didáctica de las Ciencias Sociales, (2), 4-19. https:/ / doi.org/10.17398/2531-0968.02.4

Van Dijk, T. (2019). Racismo y discurso en América Latina. Barcelona: Gedisa.

Van Leeuwen, T. (2013). The representation of social actors. In: C. Caldas y M. Coulthard (coords.). Texts and practices. Readings in critical discourse análisis (pp. 32-70). New York: Routledge.

Van Leeuwen, T. (2014). Critical discourse analysis and multimodality. In: C. Hart y P. Cap (coords.). Contemporary critical discourse analysis (pp. 281-295). London: Bloomsbury.

Vicente, D. (2020). La infancia en la antigua Mesopotamia: 25 años de investigación. Panta Rei. Revista Digital de Historia y Didáctica de la Historia, 14(2), 43-54. https:// doi.org/10.6018/pantarei.445511

Zúñiga, C. (2015). ¿Cómo se ha enseñado historia en Chile? Análisis de programas de estudio para enseñanza secundaria. Pensamiento Educativo. Revista de Investigación Educacional Latinoamericana, 52(1), 119-135. https:// doi.org/10.7764/PEL.52.1.2015.9

\section{textos escolares analizados}

Beltrán, G., Fuentes, F., Panza, P. y Valdés, C. (2019). Texto escolar de Historia, Geografía y Ciencias Sociales $7^{\circ}$ básico. Santiago de Chile: Editorial SM.

Flores, P. (2019). Texto escolar de Historia, Geografía y Ciencias Sociales $5^{\circ}$ básico. Santiago de Chile: Editorial SM.

Honeyman, S., Silva, C., Quintana, S. y Santelices, C. (2017). Texto escolar de Historia, Geografía y Ciencias Sociales $2^{\circ}$ medio. Santiago de Chile: Santillana.

Morales, J., Pastene, S., Santelices, C. y Quintana, S. (2016). Texto escolar de Historia, Geografía y Ciencias Sociales $2^{\circ}$ medio. Santiago de Chile: Santillana.

agradecimientos.

Esta investigación se enmarca en el Proyecto DIREG 07/2021 “¿Qué dicen los manuales de historia sobre la infancia? Análisis de textos escolares chilenos publicados entre los años 2016 y 2020" adscrito a la Dirección de Investigación de la Universidad Católica de la Santísima Concepción, Chile. Se agradece a la institución patrocinante por el apoyo otorgado.

recibido en: 07.10.2021

aprobado en: 12.11 .2021 